Fakultas Hukum Universitas Lancang Kuning, Jalan Yos Sudarso KM 8 Rumbai Pekanbaru, Riau, Kode Pos 28266. Telp: (+62761)-51877

E-mail: jurnal.respublica@ac.id

Website: https://journal.unilak.ac.id/index.php/Respublica

\title{
PELAKSANAAN UNDANG-UNDANG NOMOR 5 TAHUN 2014 TENTANG APARATUR SIPIL NEGARA TERHADAP PPPK YANG DILAKUKAN DI SMP NEGERI 15 PEKANBARU
}

\author{
Sudi Fahmi a , Adrian Faridhi ${ }^{b}$, Nikko Hendayana ${ }^{c}$ \\ ${ }^{a}$ Fakultas Hukum, Universitas Lancang Kuning, Indonesia, Email: sudifahmi@unilak.ac.id \\ ${ }^{\mathrm{b}}$ Fakultas Hukum, Universitas Lancang Kuning, Indonesia, Email: adrian@unilak.ac.id \\ ${ }^{\mathrm{c}}$ Fakultas Hukum, Universitas Lancang Kuning, Indonesia, Email: nikkohendayana@unilak.ac.id
}

\section{Article Info}

\section{Article History:}

Received : 01-01-2021

Revised : 20-01-2021

Accepted : 10-02-2021

Published : 28-05-2021

\section{Keywords:}

Keyword 1: Implementation

Keyword 2 : state Civil

Apparatus

Keyword 3 : PPPK

\section{Informasi Artikel}

\section{Histori Artikel:}

Diterima : 01-01-2021

Direvisi : 20-01-2021

Disetujui : 10-02-2021

Diterbitkan : 28-05-2021

\section{Kata Kunci:}

Kata Kunci 1 : pelaksanaan

Kata Kunci 2 : Aparatur Sipil Negara

Kata Kunci 3 : PPPK

\begin{abstract}
How is the implementation of Law Number 5 of 2014 concerning State Civil Apparatus against PPPK which is carried out at SMP Negeri 15 Pekanbaru. How are the obstacles and efforts in the implementation of Law Number 5 of 2014 concerning State Civil Apparatus against PPPK carried out at SMP Negeri 15 Pekanbaru. The method used is the sociological method. Its implementation has not run optimally due to inadequate budget, obstacles include lack of budget, non-linearity of education, duration of teaching time and obligations that are not different from civil servants while efforts include preparing a budget, providing a decent salary and the number of formations must also be increased.
\end{abstract}

\section{PENDAHULUAN}

\begin{abstract}
Abstrak
Bagaimana Pelaksanaan Undang-Undang Nomor 5 Tahun 2014 tentang Aparatur Sipil Negara terhadap PPPK yang dilakukan di SMP Negeri 15 Pekanbaru. Bagaimana hambatan dan upaya dalam Pelaksanaan Undang-Undang Nomor 5 Tahun 2014 tentang Aparatur Sipil Negara terhadap PPPK yang dilakukan di SMP Negeri 15 Pekanbaru. Metode yang dilakukan adalah metode sosiologis. Pelaksanaannya belum berjalan maksimal dikarenakan anggaran yang belum memadai, hambatan antara lain kurangnya anggaran,tidak linearnya pendidikan, durasi waktu mengajar dan kewajiban yang tidak berbeda dengan PNS sedangkan upayanya antara lain menyiapkan anggaran, memberikan gaji yang layak dan jumlah formasi juga harus ditambah.
\end{abstract}


Perubahan Undang-Undang Dasar Negara Kesatuan Republik Indonesi Tahun 1945 membawa perubahan disegala lini ${ }^{1}$, termasuk dalam arah reformasi Undang-Undang mengenai kepegawaian baru dilakukan revisi dengan tujuan penyempurnaan dan reformasi birokrasi dalam pemerintahan. Peraturan perundang-undangan dibuat berjenjang (hierarki) ${ }^{2}$ Melalui kajian panjang hingga pada tahun 2014 Undang-Undang mengenai Aparatur Sipil Negara dapat terwujud. Rancangan Undang-Undang mengenai Aparatur Sipil Negara (ASN) merupakan inisiatif DPR yang menjadi langkah maju dalam menghadapi realisasi terhadap reformasi dan birokrasi pemerintahan. Selama ini sejak era reformasi, hal ihwal mengenai pelaksanaan manajeman kepegawai-an ditangani oleh dua Undang-Undang yang memiliki jiwa amat berbeda, yakni Undang-Undang Nomor 8 Tahun 1974 diundangkan pada masa orde baru, sedangkan Undang-Undang Nomor 43 tahun 1999 merupakan hasil revisi pasca reformasi.

Perubahan suatu peraturan perundang-undangan harus men-datangkan manfaat yang selaras dengan tujuan hukum yang ada. Menurut G Radbruch setiap hukum yang dibuat memiliki tujuan. Tujuan hukum yang utama ada tiga, yaitu keadilan untuk keseimbangan; kepastian untuk ketepatan; dan kemanfaatan untuk kebahagiaan. Ketiga tujuan tersebut mutlak harus dipenuhi dalam suatu Undang-Undang yang berkedudukan sebagai hukum bagi setiap orang.

Pelaksanaan Undang-Undang Nomor 5 Tahun 2014 mempengaruhi kedudukan dan perlindungan hukum bagi tenaga honorer sebab dalam ketentuannya istilah tenaga honorer dihapuskan. ${ }^{3}$ Dibandingkan dengan Undang-Undang kepegawaian sebe-lumnya yaitu Undang-Undang Nomor 43 Tahun 1999 mengkalsifi-kasikan bahwa pegawai Negeri sebagaimana yang tercantum dalam Pasal 2 ayat (1) adalah: a. Pegawai Negeri Sipil; b. Anggota Tentara Nasional Indonesia; dan c. Anggota Kepolisian Negara Republik Indonesia.

\footnotetext{
1 Sudi Fahmi, Adrian Faridhi, “Limited Amendment of 1945 Basic Constitution and The Return of Main State Guidelines” Jurnal Mimbar, Vol.36 . No. 1 Tahun 2020, hlm. 84.

2 Adrian Faridhi, "Penguji Peraturan Perundang-undangan Tunggal Keniscayaan”, Jurnal Mecatoria, Vol.10 No. 2 Tahun 2017, hlm.181.

${ }^{3}$ Dicky A Saputro, Sudarsono, dan Lutfi Efendi, Kedudukan dan Perlindungan Hukum Tenaga Honorer Setelah Berlakunya Undang-Undang Nomor 5 tahun 2014, hlm. 4.
} 
Kemudian pada Pasal 2 ayat (3) disebutkan bahwa "di samping Pegawai Negeri sebagaimana dimaksud dalam ayat (1) pejabat yang berwenang dapat mengangkat pegawai tidak tetap". Artinya dalam menjalankan suatu roda pemerin-tahan pejabat yang berwenang diberikan kewenangan untuk meng-angkat pegawai tidak tetap yang kemudian disebut tenaga honorer, dalam mempermudah beban kerja Pegawai Negeri dan untuk tujuan lainnya sepanjang tidak bertentangan dengan Undang-Undang.

Pegawai Negeri Sipil (PNS) merupakan warga negara Indonesia yang memenuhi syarat tertentu, yang diangkat sebagai pegawai tetap oleh Pejabat Pembina Kepegawaian untuk mendu-duki jabatan pemerintahan dan memiliki nomor induk pegawai secara nasional. Sedangkan Pegawai Pemerintah dengan Perjanjian Kerja (PPPK) yaitu warga negara Indonesia yang memenuhi syarat tertentu, yang diangkat berdasarkan perjanjian kerja untuk jangka waktu tertentu dalam rangka melaksanakan tugas peme-rintahan.

PPPK dengan Pegawai honorer memiliki kedudukan hampir sama, namun tidak serta secara otomatis bagi pegawai honorer sekarang dapat langsuang menjadi PPPK. Dikarena secara prinsip kedua jenis pegawai ini sangat berbeda, yakni PPPK diangkat dengan suatau perjanjian kerja yang jelas.

Berdasarkan Undang-Undang Nomor 5 Tahun 2014 tentang Aparatur Sipil Negara Pasal 22 menyebutkan bahwa PPPK berhak memperoleh; a. gaji dan tunjangan; b. cuti; c. perlin-dungan; dan d. pengembangan kompetensi. Akan tetapi pada kenyataannya, di SMP Negeri 15 Pekanbaru, untuk PPPK mendapatkan gaji rapelan, kemudian tidak mendapat tunjangan serta mengenai pengangkatan tidak ada kepastian yang diberikan untuk PPPK.

Menurut Azwar Abu Bakar (Mantan Mentri PAN-RB), dengan adanya Undang-Undang Aparatur Sipil Negara tidak ada lagi pegawai honorer/pegawai tidak tetap, yang dikenal dalam Undang-Undang No. 5 Tahun 2014 adalah PNS dan Pegawai Pemerintah dengan Perjanjian Kerja (PPPK). Hal ini berarti tidak ada kejelasan status dan jaminan hukum tenaga honorer diangkat menjadi PNS atau PPPK, karena proses rekrutmen PNS dan PPPK harus mengikuti peraturan seperti; harus dilaksanakan secara terbuka, mengedepankan kete-rampilan dan kecakapan, berdasarkan analisis jabatan dan proyeksi kebutuhan pegawai yang jelas, evaluasi beban kerja, dan lain sebagainya.

Setelah berlakunya Undang-Undang Nomor 5 Tahun 2014 istilah Pegawai Negeri Sipil diganti dengan Pegawai Aparatur Sipil Negara atau disingkat Aparatur Sipil Negara. Pegawai 
Aparatur Sipil Negara adalah pegawai negeri sipil dan pegawai tidak tetap pemerintah yang diangkat oleh pejabat yang berwenang secara kompetitif berdasarkan asas merit, dan diserahi tugas untuk melaksanakan tugas-tugas pemerintahan dan tugas pembangunan negara, professional, memiliki nilai-nilai dasar, etika profesi, bebas dari intervensi politik, bersih dari praktik korupsi, kolusi dan nepotisme $(\mathrm{KKN})$ serta digaji berdasarkan ketentuan peraturan perundang-undangan. ${ }^{4}$

Berdasarkan pengertian Pega-wai Negeri di dalam peraturan perundang-undangan yang mengatur tentang Pokok-pokok Kepegawaian, dapat dilihat adanya unsur-unsur yang harus dipenuhi dari seseorang untuk dapat diangkat sebagai pegawai negeri.

Berikut adalah unsur-unsur yang harus dipenuhi agar dapat diangkat sebagai sebagai pegawai negeri, yaitu sebagai berikut $:^{5}$

a) Warga Negara Republik Indonesia yang telah meme-nuhi syarat yang ditentukan dalam peraturan perundang-undangan;

b) Diangkat oleh pejabat yang berwenang;

c) Diserahi tugas dalam suatu jabatan negeri atau diserahi tugas lainnya;

d) Digaji berdasarkan peraturan perUndang-Undang an.

Menurut Undang-Undang Nomor 5 Tahun 2014 Tentang Aparatur Sipil Negara Pasal 10, menyebutkan mengenai fungsi Aparatur Sipil Negara, yaitu:

a. Pelaksana kebijakan publik;

b. Pelaksana pelayanan publik; dan

c. Perekat dan pemersatu bangsa.

Adapun tugas dari Aparatur Sipil Negara dijelaskan pada pasal 11, yaitu:

a. Melaksanakan kebijakan pub-lik yang dibuat oleh Pejabat Pembina Kepegawaian sesuai dengan ketentuan peraturan perundang-undangan;

b. Memberikan pelayanan publik yang professional dan berkualitas; dan

c. Mempererat persatuan dan kesatuan Negara Kesatuan Republik Indonesia.

Kemudian adapun peran dari Aparatur Sipil Negara dijelaskan pada pasal 12, yaitu:

Pegawai Aparatur Sipil Negara berperan sebagai perencana, pelak-sana, dan pengawas penyelenggara tugas umum pemerintahan dan pembagunan nasional melalui pelaksanaan

${ }^{4}$ Faisal Abdullah, Hukum Kepegawaian Indonesia, (Yogyakarta: Rangkang Education Yogyakarta \& PuKAP-Indonesia, 2015), hlm. 3.

${ }^{5}$ Faisal Abdullah, Op.Cit., hlm.4. 
kebijakan dan pelayanan publik yang professional, bebas dari intervensi politik, serta bersih dari praktir korupsi, kolusi, dan nepotisme.

Selain itu, Menurut Undang-Undang Nomor 5 Tahun 2014 Tentang Aparatur Sipil Negara Pasal 21 menyebutkan bahwa PNS berhak memperoleh :

a. gaji, tunjangan, dan fasilitas; (Pasal 79)

b. cuti;

c. jaminan pensiun dan jaminan hari tua; (Pasal 91)

d. perlindungan; (Pasal 92)

e. pengembangan kompetensi. (Pasal 69)

Hak yang diperoleh Aparatur Sipil Negara harus beriringan dengan kewajibannya yang telah , diatur dalam pasal 23 Undang-Undang Nomor 5 Tahun 2014, yaitu:

a. Setia dan taat pada Pancasila, Undang-Undang Dasar Negara Republik Indonesia Tahun 1945, Negara Kesatuan Rep-ublik Indonesia, dan pemeri-ntah yang sah;

b. Menjaga persatuan dan kesa-tuan bangsa;

c. Melaksanakan kebijakan yang dirumuskan pejawab pemerin-tah yang berwenang;

d. Mentaati ketentuan peraturan perundang-undangan;

e. Melaksanakan tugas kedinasan dengan penuh pengabdian, kejujuran, kesadaran, dan tanggung jawab;

f. Menunjukkan integritas dan keteladanan dalam sikap, perilaku, ucapan dan tindakan kepada setiap orang, baik di dalam maupun di luar kedinasan;

g. Menyimpan rahasia jabatan dan hanya dapat mengemuka-kan rahasia jabatan sesuai dengan ketentuan perundang-undangan; dan

h. Bersedia ditempatkan di selu-ruh wilayah Negara Kesatuan Republik Indonesia.

Selebihnya mengenai Pegawai Negeri Sipil diatur dan dijelaskan lebih rinci didalam Peraturan Peme-rintah Republik Indonesia Nomor 11 Tahun 2017 tentang Manajemen Pegawai Negeri Sipil.

\section{A. Tenaga Kontrak Pegawai Pemerintah}

Setelah berlakunya Undang-Undang Nomor 5 Tahun 2014 istilah Tenaga Kontrak Pegawai Pemerintah atau yang bisa juga disebut dengan Pegawai Honorer berubah istilahnya menjadi Pegawai Pemerintah dengan Perjanjian Kerja (PPPK). 
PPPK sebagaimana dimaksud dalam Pasal 6 huruf b merupakan Pegawai Aparatus Sipil Negara yang diangkat sebagai pegawai dengan perjanjian kerja oleh Pejabat Pembina Kepegawaian sesuai dengan kebutuhan Instansi Pemerintah dan ketentuan Undang-Undang ini.

Kemudian berdasarkan Peraturan Pemerintah Republik Indonesia Nomor 49 Tahun 2018 tentang Manajemen Pegawai Pemerintah dengan Perjanjian Kerja menjelaskan PPPK adalah warga negara Indonesia yang memenuhi syarat tertentu, yang diangkat berdasarkan perjanjian kerja untuk jangka waktu tertentu dalam rangka melaksanakan tugas pemerintah.

Adapun hak dari PPPK ialah: ${ }^{6}$

a. Gaji dan tunjangan

b. Cuti

c. Perlindungan, dan

d. Pengembangan kompetensi

Pegawai Pemerintah dengan pengangkatan berdasarkan Perjanjian Kerja diketahui bahwa tidak berkedudukan sebagai pegawai negeri karena pegawai tersebut diangkat untuk jangka waktu tertentu guna melaksanakan tugas dan pekerjaannya. Rekrutmen terhadap PPPK merupakan salah satu bentuk antisipasi yang dilakukan oleh pemerintah terhadap tingginya jumlah kebutuhan pegawai tetapi harus tetap memperhatikan keter-batasan dana yang disediakan oleh APBN/APBD karena sistem penggajian PPPK diambil dari dana APBN / APBD. Menurut Prasojo, tujuan dari rekrutmen PPPK adalah untuk memperkuat basis profesi-onalisme dan kompetensi dalam penyelenggaraan birokrasi. Dengan kata lain masuknya PPPK pada Aparatur Sipil Negara diharapkan dapat mendorong percepatan atau akselerasi dalam menciptakan profesionalisme dan peningkatan kompetensi PNS. ${ }^{7}$

Dalam penelitian ini jenis penelitian yang dipakai adalah penelitian hukum sosiologis, yang membahas tentang Pelaksanaan Undang-Undang Nomor 5 Tahun 2014 tentang Aparatur Sipil Negara terhadap PPPK yang dilakukan di SMP Negeri 15 Pekanbaru.

\section{HASIL DAN PEMBAHASAN}

\section{A. Pelaksanaan Undang-Undang Nomor 5 Tahun 2014}

Setelah berlakunya Undang-Undang Nomor 5 Tahun 2014, mem-buat kedudukan tenaga honorer menjadi tidak jelas. Karena kedudu-kan tenaga honorer kemudian digan-tikan

\footnotetext{
${ }^{6}$ Pasal 22 Undang-Undang Nomor 5 Tahun 2014 Tentang Aparatur Sipil Negara

${ }^{7}$ Agustinus Sulistyo Tri Putranto, "Pegawai Pemerintah Dengan Perjanjian Kerja: Pengertian dan Urgensinya”, Jurnal Kebijakan dan Manajemen PNS, vol.9 No.2, November 2015, Hlm. 2.
} 
oleh pemerintah menjadi Pega-wai Pemerintah dengan Perjanjian Kerja dan secara tidak langsung kedudukan tenaga honorer menjadi hilang.

Terkait dengan jabatan yang dapat diisi oleh Pegawai Pemerintah dengan Perjanjian Kerja diatur dalam Peraturan Presiden dan setiap instansi pemerintah wajib menyusun kebutuhan jumlah dan jenis jabatan untuk Pegawai Pemerintah dengan perjanjian Kerja berdasarkan analisis jabatan dan analisis beban kerja. Hal ini disebutkan dalam pasal 94 ayat 1 dan 2 Undang-Undang Nomor 5 tahun 2014 tentang Aparatur Sipil Negara.

Berdasarkan undang-undang, Pegawai Pemerintah dengan Perjan-jian Kerja berhak menerima gaji dan tunjangan dari pemerintah berdasar-kan beban kerja, tanggung jawab jabatan, dan resiko pekerjaan. Beban anggaran gaji pegawai pemerintah dengan perjanjian kerja dibebankan pada APBN/APBD sesuai dengan pasal 101 Undang-Undang Nomor 5 tahun 2014 tentang Aparatur Sipil Negara.

Akan tetapi pada kenyataannya pelaksanaan Undang-Undang No. 5 Tahun 2014 Tentang Aparatur Sipil Negara Terhadap PPPK Di SMP Negeri 15 Pekanbaru sepenuhnya belum berjalan dengan lancar. ${ }^{8}$ Di karenakan anggaran yang berasal dari Pemerintah Kota belum cukup untuk memenuhi kebutuhan ang-garan membiayai PPPK yang ada di Kota Pekanbaru. Kemudian Di SMP Negeri 15 Pekanbaru Pegawai Pemerintah dengan Perjanjian Kerja hanya dibayar dengan sesuai dengan gaji minimal Rp 1.000 .000 serta banyaknya jam mengajar, maka semakin banyak jam mengajarnya, semakin besar pula gaji yang didapatkan. ${ }^{9}$ Padahal seharusnya PPPK mendapatkan gaji yang sesuai dengan Keputusan Gubernur Riau Nomor: Kpts.1198/XI/2019 tentang UMK 2020, yaitu sebesar Rp 2.997.976.

Adapun total jam mengajar PPPK di SMP Negeri 15 Pekanbaru perminggu, berikut ini:

${ }^{8}$ Hasil wawancara dengan Kepala Sekolah SMP Negeri 15 Pekanbaru, Bapak Yunus, S.Pd., pada hari Rabu, 22 April 2020, di SMP Negeri 15 Pekanbaru.

${ }^{9}$ Hasil wawancara dengan PPPK SMP Negeri 15 Pekanbaru, Ibu Putri Prima, S.Pd., pada hari Rabu, 22 April 2020, di Jl. Limbungan. 
Tabel 2: Tabel Jam Mengajar PPPK di SMP Negeri 15 Pekanbaru

\begin{tabular}{|c|l|c|}
\hline No & \multicolumn{1}{|c|}{ Nama } & $\begin{array}{l}\text { Total Jam } \\
\text { Mengajar }\end{array}$ \\
\hline 1 & $\begin{array}{l}\text { Hocky } \\
\text { Saputra, } \\
\text { S.Kom }\end{array}$ & 28 Jam \\
\hline 2 & $\begin{array}{l}\text { Nurlaili } \\
\text { Moniza, } \\
\text { S.Hum }\end{array}$ & 18 Jam \\
\hline 3 & $\begin{array}{l}\text { Meri Marlina, } \\
\text { S.Pd }\end{array}$ & 18 Jam \\
\hline 4 & $\begin{array}{l}\text { Indra Astuti, } \\
\text { S.Ag }\end{array}$ & 21 Jam \\
\hline 5 & $\begin{array}{l}\text { Poppy } \\
\text { Herfana, } \\
\text { M.Pd }\end{array}$ & 15 Jam \\
\hline 6 & $\begin{array}{l}\text { Nurul Mona, } \\
\text { S.Pd }\end{array}$ & 16 Jam \\
\hline 7 & $\begin{array}{l}\text { Gerizof } \\
\text { Jevilio, S.Pd }\end{array}$ & $\begin{array}{l}\text { 15 Jam } \\
\text { Aemala } \\
\text { S.Pd }\end{array}$ \\
\hline 9 & $\begin{array}{l}\text { Putri Prima, } \\
\text { S.Pd }\end{array}$ & $\begin{array}{l}\text { 15 Jam } \\
\text { Asri, S.Pd }\end{array}$ \\
\hline 10 & $\begin{array}{l}\text { Okni Susanti } \\
\text { S, S.Pd.K }\end{array}$ & 27 Jam \\
\hline 11 & $\begin{array}{l}\text { Nidia Septia } \\
\text { N.Pd }\end{array}$ & 18amaroh \\
\hline 12 & 15am \\
\hline
\end{tabular}

Kemudian terjadi ketika lineran bidang studi yang diajari dengan jurusan yang dipahami oleh Pegawai Pemerintah dengan Perjanjian Kerja yang berada di SMP Negeri 15 Pekanbaru, 
salah contohnya seperti PPPK yang membidangi pelajaran Bahasa Indonesia, harus mengajar menjadi pelajaran Bahasa Inggris. ${ }^{10}$

Seharusnya, dengan ditetap-kannya peraturan pemerintah dari Undang-Undang Aparatur Sipil Negara tersebut dapat memberikan kepastian hukum mengingat banyak penafsiran terhadap PPPK berdasar-kan Undang-Undang Aparatur Sipil Negara. Salah satunya penafsiran dari banyak pihak yang mengartikan bahwa PPPK merupakan pengganti pegawai honorer karena status dan pengaturannya yang kurang jelas. Selain itu, banyak pertanyaan me-ngenai proses pengangkatan seseo-rang sebagai PPPK serta jabatan-jabatan apa saja yang berpeluang diisi oleh PPPK dalam sistem penyelenggaraan pemerintah-an pada instansi pemerintahan tertentu. Adapun juga kewajiban pada PPPK yang tidak berbeda dengan PNS, padahal seharusnya antara PPPK dan PNS mempunyai kewajiban yang berbeda karena dari segi jam mengajar serta gaji saja tidak sesuai dengan ketentuan yang ada.

Kemudian keterangan yang penulis dapatkan dari Ombusdman Pekanbaru, bahwa pihak dari Ombusdman belum bisa memberikan informasi terkait PPPK di SMP Negeri 15 Pekanbaru dikarenakan belum adanya aduan yang sampai kepada Ombusdman Pekanbaru. ${ }^{11}$

Maka dari itu, penulis menarik kesimpulan bahwa pelaksanaan Undang-Undang No. 5 Tahun 2014 Tentang Aparatur Sipil Negara Terhadap PPPK Di SMP Negeri 15 Pekanbaru belum terlaksana dengan baik.

\section{B. Faktor Penghambat dalam Pelaksanaan Undang-Undang Nomor 5 Tahun 2014}

Dalam pelaksanaan Undang-Undang Nomor 5 Tahun 2014 tentang Aparatur Sipil Negara terhadap PPPK di SMP Negeri 15 Pekanbaru memiliki beberapa ham-batan. Adapun hambatan tersebut ialah:

\section{Kurangnya Anggaran}

Adapun kurangnya anggaran menjadi hambatan, karena gaji dan tunjangan untuk Pegawai Pemerintah dengan Perjanjian Kerja berasal dari anggaran yang disediakan oleh Anggaran Pendapatan, dan Belanja Daerah (APBD) yaitu Pemerintah Kota Pekanbaru

${ }^{10}$ Hasil wawancara dengan Kepala Sekolah SMP Negeri 15 Pekanbaru, Bapak Muhammad Yunus, S.Pd., pada hari Rabu, 22 April 2020, di SMP Negeri 15 Pekanbaru.

${ }^{11}$ Hasil wawancara melalui aplikasi WhatsApp dengan Admin Ombusdman Pekanbaru, Bapak Ricki, pada 8 April 2020. 
terhambat yang menyebabkan gaji PPPK di SMP Negeri 15 Pekanbaru menjadi dirapel atau dengan kata lain diterimakan sekaligus dikemudian hari. ${ }^{12}$

Pemerintah pusat sudah berupaya untuk mengalokasikan dana anggaran untuk diberikan kepada PPPK yang berasal dari Anggaran Pendapatan, dan Belanja Daerah akan tetapi pada kenyataaannya anggaran tersebut tetap saja kurang untuk memenuhi kebutuhan PPPK.

Dari situs resmi Kementrian Keuangan, pemerintah mengalokasi-kan tambahan DAU untuk gaji PPPK senilai 4,260 Triliun Rupiah. Terdapat tambahan DAU sebagai dukungan pendanaan terkait kebi-jakan penggajian PPPK, bunyi pasal 11 ayat 19 Undang-Undang Nomor 20 Tahun 2019 tentang Anggaran Pendapatan dan Belanja Negara Tahun Anggaran 2020. Berdasarkan pasal 101 ayat 3 Undang-Undang Nomor 5 Tahun 2014 tentang Aparatur Sipil Negara, dinyatakan gaji PPPK dibebankan pada APBN untuk PPPK instansi pusat. Sedangkan, gaji PPPK daerah diang-garkan melalui APBD. ${ }^{13}$

2. Gaji Yang Tidak Sesuai

Berdasarkan Keputusan Guber-nur Riau Nomor: KPTS.1198-/XI/2019 tentang UMK 2020, Upah minimum untuk Kota Pekanbaru ialah $\mathrm{Rp}$ 2.997.976, sedangkan pada kenyataannya gaji yang didapatkan oleh PPPK di SMP Negeri 15 Pekanbaru hanya dibayar sesuai jam jam mengajar, dengan manimal gaji $\mathrm{Rp} 1.000 .000 .{ }^{14}$

Untuk mengeluarkan gaji para PPPK yang sesuai dengan UMK pun harus melalui dan berdasarkan dari kewenangan dari pemerintah daerah dan dari pusat harus dirumuskan, namun kembali lagi kepada pembahasan sebelumnya gaji PPPK masih belum terpenuhi karena masih kurangnya anggaran yang berasal dari pemerintah pusat.

Gaji di tahun ajaran 2017/2018, jumlah jam mengajar 30 jam, bulan Juli 2017 sampai dengan Juni 2018, 30 jam x Rp $30.000=R p$ 900.000/perbulan. Gaji di tahun ajaran 2018/2019 jumlah jam mengajar 24 jam, bulan Juli sampai dengan Desember 2018, 24 jam x Rp $30.000=\operatorname{Rp~720.000/perbulan.~Bulan~Januari~sampai~dengan~Juni~2019,~} 24$ jam x Rp $40.000=$ Rp 960.000/perbulan. Gaji di tahun ajaran 2019/2020, jumlah jam mengajar 18 jam,

\footnotetext{
${ }^{12}$ Hasil wawancara dengan Ketua DPRD Komisi III, Bapak Yasser Hamidy, S.Pi., pada hari Senin, 23 Maret 2020, di DPRD Kota Pekanbaru.

${ }^{13}$ https://gemasulawesi.com/empat-triliun-rupiah-anggaran-gaji-pppk-dalam-dau-2020/amp/ diakses pada hari. Minggu 3 April 2020.

${ }^{14}$ Hasil wawancara dengan PPPK SMP Negeri 15 Pekanbaru, Ibu Meri Marlina, S.Pd., pada hari Kamis, 30 April 2020, melalui Aplikasi WhatsApp (08239187xxxx).
} 
bulan Juli sampai dengan Desember 2019, 18 jam x Rp 40.000= Rp 720.000 perbulan. Bulan Januari sampai dengan Mei 2020, 18 jam x Rp 50.000 = Rp 900.000/perbulan. ${ }^{15}$

3. Status Menjadi Pegawai

Sejak tahun 2014 hingga tahun 2020 belum ada penganggakatan PPPK menjadi Aparatur Sipil Negara di SMP Negeri 15 Pekanbaru, karena belum adanya penganggkatan dari pusat ataupun dari Pemerintah. ${ }^{16}$ Padahal seharusnya PPPK diberikan kepastian mengenai SK Pengang-katannya menjadi Aparatur Sipil Negara.

Untuk menjadi pegawai, PPPK harus melalui beberapa tahapan lagi seperti ikut pelatihan bahwa mereka sudah sesuai untuk mendapatkan statusnya menjadi pegawai, padahal PPPK di SMP Negeri 15 Pekanbaru, sudah dapat memenuhi syarat untuk menjadi pegawai, akan tetapi belum juga mendapatkan haknya menjadi pegawai.

4. Tidak Linear Bidang Pendidikan

Di SMP Negeri 15 Pekanbaru terjadi ketidak linearan PPPK terhadap bidang pendidikan yang diajarkan, contohnya seperti satu PPPK harus mengajar bidang pendidikan bahasa Inggris, padahal bidang yang dikuasai ataupun yang sesuai dengan PPPK tersebut ialah matematika. ${ }^{17}$ Hal itu dikarenakan masih kurangnya formasi PPPK untuk mengajar pada satu bidang pendidikan. ${ }^{18}$

Ketidak linearan bidang pendi-dikan dipengaruhi oleh kurangnya PPPK yang berada di SMP Negeri 15 Pekanbaru, sehingga PPPK menga-jarkan yang tidak sesuai dengan bidang kompetensinya padahal hal tersebut dapat mempengaruhi dalam masa pembelajaran.

\section{Durasi Waktu Mengajar}

Peraturan Menteri Pendidikan dan Kebudayaan Nomor 15 Tahun 2018 tentang Pemenuhan Beban Kerja Guru, Kepala Sekolah dan Pengawas, dimana didalam peraturan tersebut guru wajib melaksanakan jam kerja 40 jam dalam seminggu (Senin-Sabtu bagi sekolah yang menerapkan 6 hari kerja dalam seminggu atau Senin-Jum'at bagi sekolah yang menerapkan 5 hari kerja dalam seminggu). Sebenarnya hal ini tidak perlu dihebohkan karena peraturan tersebut berlaku untuk seluruh PNS sejak dahulu kala. Guru, Kepala Sekolah dan

\footnotetext{
${ }^{15}$ Hasil wawancara dengan PPPK SMP Negeri 15 Pekanbaru, Ibu Putri Prima, S.Pd., pada hari Rabu, 22 April 2020, di Jl. Limbungan.

${ }^{16}$ Hasil wawancara dengan PPPK SMP Negeri 15 Pekanbaru, Ibu Putri Prima, S.Pd., pada hari Rabu, 22 April 2020, di Jl. Limbungan.

${ }^{17}$ Hasil wawancara dengan Kepala Sekolah SMP Negeri 15 Pekanbaru, Bapak Yunus, S.Pd., pada hari Rabu, 22 April 2020, di SMP Negeri 15 Pekanbaru.

${ }^{18}$ Hasil wawancara dengan Ketua DPRD Komisi III, Bapak Yasser Hamidy, S.Pi., pada hari Senin, 23 Maret 2020, di DPRD Kota Pekanbaru.
} 
Pengawas adalah PNS. Oleh karena itu harus patuh terhadap aturan yang mengatur PNS secara umum, selain juga harus mematuhi aturan-aturan yang menyangkut profesi sebagai guru, kepala sekolah dan Pengawas.

Sebagai tenaga pengajar harus mematuhi Keputusan Presiden Nomor 68 Tahun 1995 tentang Hari Kerja Di Lingkungan Lembaga Pemerintah, dimana didalam Pasal 1 ayat (2) dinyatakan bahwa jumlah jam kerja efektif PNS dalam seminggu adalah 37,5 jam. Sedangkan sebagai guru (juga Kepala Sekolah dan Pengawas) telah diterbitkan Peraturan Menteri Pendidikan dan Kebudayaan Nomor 15 Tahun 2018 tentang Pemenuhan Beban Kerja Guru, Kepala Sekolah, dan Pengawas Sekolah, dimana didalam Pasal 2 (1) Guru, Kepala Sekolah, dan Pengawas Sekolah melaksanakan beban kerja selama 40 (empat puluh) jam dalam 1 (satu) minggu pada satuan administrasi pangkal, dan (2) Beban kerja selama 40 (empat puluh) jam dalam 1 (satu) minggu sebagaimana dimaksud pada ayat (1) terdiri atas 37,5 (tiga puluh tujuh koma lima) jam kerja efektif dan 2,5 (dua koma lima) jam istirahat. Dengan demikian bagi sekolah yang melaksanakan 6 hari kerja berarti jam kerja efektif setiap harinya adalah 37,5 jam dibagi 6 sama dengan 6,25 jam (6 jam 15 menit), sedangkan jam istirahatnya setiap hari adalah 2,5 jam dibagi 6 sama dengan 0,4 jam (=24 menit). Maka jam efektif ditambah jam istirahat sama dengan 6 jam 39 menit (atau dibulatkan 6 jam 40 menit). Ini berarti jika sekolah menjadwalkan masuk jam 07.00 maka pulangnya jam 13.40.

Adapun durasi mengajar PPPK di SMP Negeri 15 Pekanbaru, hampir sama dengan PNS yang berada di SMP Negeri 15 Pekanbaru, padahal gaji yang PPPK dapatkan saja tidak sesuai dengan jam mengajarnya. ${ }^{19}$

6. Kewajiban Tidak Berbeda Dengan PNS.

PPPK di SMP Negeri 15 Pekanbaru mempunyai kewajiban yang sama dengan PNS di SMP Negeri 15 Pekanbaru, yaitu untuk merencanakan pembelajaran, melak-sanakan proses pembelajaran yang bermutu, serta menilai dan meng-evaluasi hasil pembelajaran, padahal seperti pembahasan sebelumnya dari segi status dan gaji saja PPPK dan PNS di SMP Negeri 15 Pekanbaru berbeda. ${ }^{20}$

\footnotetext{
${ }^{19}$ Hasil wawancara dengan PPPK SMP Negeri 15 Pekanbaru, Ibu Okni Susanti Simanjuntak, S.Pd.K., pada hari Kamis, 30 April 2020, melalui Aplikasi WhatsApp (08127563xxxx).

${ }^{20}$ Hasil wawancara dengan PPPK SMP Negeri 15 Pekanbaru, Ibu Meri Marlina, S.Pd., pada hari Kamis, 30 April 2020, melalui Aplikasi WhatsApp (08239187xxxx).
} 
Sudah jelas dari segi status PPPK dan PNS berbeda, akan tetapi mereka tetap menjalankan kewajib-annya yaitu untuk mencerdaskan bangsa walaupun PPPK mempunyai kendala dari segi ketidak linearan bidang studi serta ketidak jelasan status menjadi pegawai.

Inilah yang menjadi bagian dari jalan pahlawan bangsa tanpa tanda jasa, salah satunya ialah tenaga pengajar PPPK, walaupun mereka kurang diperhatikan oleh Pemerintah, baik itu dari segi upah maupun kejelasan status, tidak membuat mereka berhenti untuk mencerdaskan anak bangsa.

\section{Upaya Mengatasi Hambatan dalam Pelaksanaan Undang-Undang Nomor 5 Tahun 2014}

Upaya dalam mengatasi hambatan dalam pelaksanaan Undang-Undang Nomor 5 Tahun 2014 Tentang Aparatur Sipil Negara Terhadap PPPK di SMP Negeri 15 Pekanbaru:

1. Menyiapkan anggaran formasi khusus PPPK atau guru dan harus berjalan efektif oleh pemerintah Kota Pekanbaru, untuk mengatasi hambatan yang terjadi sampai saat ini. ${ }^{21}$ Serta antara Pemerintah yaitu DPRD Kota Pekanbaru dengan Dinas Pendidikan Kota Pekanbaru harus berkolaborasi dalam menangani pembahasan anggaran untuk para PPPK, baik yang ada di SMP Negeri 15 Pekanbaru, maupun di seluruh Kota Pekanbaru. $^{22}$

2. Pemerintah seharusnya mem-berikan gaji yang layak, paling tidak sesuai dengan upah minimum dari masing-masing daerah, karena upah minimum merupakan nominal gaji yang paling kecil untuk diberikan kepada pekerja sesuai dengan kebutuhan hidupnya. Jika hal ini dilakukan pemerintah, maka hak-hak dari pegawai tidak tetap yang ada diinstansi pemerintahakan lebih terjamin. Secara tidak langsung, pem-berian gaji yang layak akan lebih meningkatkan semangat kerja dari pegawai tidak tetap tersebut. Dan juga mereka akan merasa dihargai dengan gaji yang sesuai dengan tenaga yang digunakan sebagai tenaga pengajar.

3. Mengenai SK penganggakatan menjadi Aparatur Sipil Negara, Dinas Pendidikan Kota Pekanbaru tetap berkoordinasi dengan Kementerian Pendaya-gunaan Aparatur Negara

${ }^{21}$ Hasil wawancara dengan Ketua DPRD Komisi III, Bapak Yasser Hamidy, S.Pi., pada hari Senin, 23 Maret 2020, di DPRD Kota Pekanbaru.

${ }^{22}$ Hasil wawancara dengan Kepala Dinas Pendidikan Kota Pekanbaru, yang diwakilkan oleh Kepada Bagian Umum Dinas Pendidikan Kota Pekanbaru, Bapak Irfan Maidelis, pada hari Rabu, 18 Maret 2020, di Dinas Pendidikan Kota Pekanbaru. 
dan Reformasi Birokrasi Republik Indonesia (Kemenpan RB) dan Badan Kepegawaian dan Pengembangan Sumber Daya Manusia Kota Pekanbaru. ${ }^{23}$

4. Jumlah formasi PPPK di SMP Negeri 15 Pekanbaru seharus-nya ditambah untuk memenuhi bidang pendidikan yang di-ajarkan, agar tidak ada PPPK yang mengajar bidang pendidikan yang tidak sesuai dengan kemampuannya atau dengan bidang pendidikan yang dikuasai. ${ }^{24}$ Dengan ditambahkannya formasi PPPK ,maka dapat menunjang pem-belajaran yang sesuai untuk para siswa, serta PPPK dapat mengajarkan sesuai dengan bidang kompetensi yang dimilikinya.

5. Durasi waktu mengajar sebaik-nya disesuaikan dengan gaji yang didapatkan, agar PPPK yang berada di SMP Negeri 15 Pekanbaru, juga mendapatkan kesejahteraan. ${ }^{25}$ Serta diberikan gaji tambahan apabila durasi mengajar lebih dari yang seharusnya.

6. Kewajibannya PPPK dengan PNS di SMP Negeri 15 Pekanbaru, dapat disamakan, akan tetapi sama seperti pembahasan sebelumnya PPPK juga harus mendapatkan gaji yang sesuai dengan peker-jaannya. ${ }^{26}$ Selain itu, apabila PPPK harus menjalankan kewajiban yang sama dengan PNS sebaiknya mereka juga diberikan kejelasan untuk menjadi pegawai, agar di dalam menjalankan kewajiban-nya, para PPPK memperoleh motivasi dan semangat dalam menjalankan tugasnya sebagai tenaga pengajar di SMP Negeri 15 Pekanbaru.

\section{KESIMPULAN}

Pelaksanaan Undang-Undang Nomor 5 Tahun 2014 tentang Aparatur Sipil Negara terhadap PPPK di SMP Negeri 15 Pekanbaru belum terlaksana dengan baik. Faktor penghambat dalam Pelaksanaan Undang-Undang Nomor 5 Tahun 2014 tentang Aparatur Sipil Negara Terhadap PPPK Di SMP Negeri 15 Pekanbaru, ialah anggaran dari Pemerintah Kota tidak cukup, ketidak linearan bidang pendidikan yang dikuasi oleh PPPK, gaji yang tidak sesuai dengan UMK, durasi waktu mengajar, status menjadi pegwai, dan kewajibannya yang tidak berbeda dengan PNS.

${ }^{23}$ Hasil wawancara dengan Kepala Dinas Pendidikan Kota Pekanbaru, yang diwakilkan oleh Kepada Bagian Umum Dinas Pendidikan Kota Pekanbaru, Bapak Irfan Maidelis, pada hari Rabu, 18 Maret 2020, di Dinas Pendidikan Kota Pekanbaru.

${ }^{24}$ Hasil wawancara dengan PPPK SMP Negeri 15 Pekanbaru, Ibu Putri Prima, S.Pd., pada hari Rabu, 22 April 2020, di Jl. Limbungan.

${ }^{25}$ Hasil wawancara dengan PPPK SMP Negeri 15 Pekanbaru, Ibu Okni Susanti Simanjuntak, S.Pd.K., pada hari Kamis, 30 April 2020, melalui Aplikasi WhatsApp (08127563xxxx).

${ }^{26}$ Hasil wawancara dengan PPPK SMP Negeri 15 Pekanbaru, Ibu Meri Marlina, S.Pd., pada hari Kamis, 30 April 2020, melalui Aplikasi WhatsApp (08239187xxxx). 
Selain itu upaya yang dapat dilakukan untuk mengatasi hambatan dalam Pelaksanaan Undang-Undang Nomor 5 Tahun 2014 tentang Aparatur Sipil Negara terhadap PPPK di SMP Negeri 15 Pekanbaru, yaitu menyiapkan anggaran khusus buat formasi khusus PPPK atau guru dan harus berjalan efektif oleh Pemerintah Kota Pekanbaru dan Dinas Pendidikan Kota Pekanbaru tetap berkoordinasi dengan Kemenpan RB) dan BKPSDM Kota Pekanbaru mengenai SK pengang-katan, memberikan kejelasan status kepada PPPK, memberikan gaji yang sesuai, serta penyesuaian jam mengajar dan kewajiban PPPK di SMP Negeri 15 Pekanbaru.

\section{REFERENSI}

Adrian Faridhi, "Penguji Peraturan Perundang-undangan Tunggal Keniscayaan”, Jurnal Mecatoria, Volume 10, No.2 Desember 2017.

Agustinus Sulistyo Tri Putranto, "Pegawai Pemerintah Dengan Perjanjian Kerja: Pengertian dan Urgensinya”, Jurnal Kebijakan dan Manajemen PNS, vol.9 No.2, November 2015

Azwar Abu Bakar dalam Titin Fatimah dan Gusminarti, 2015, Status Hukum Tenaga Honorer Setelah Lahirnya Undang-Undang No. 5 Tahun 2014 tentang Aparatur Sipil Negara. Bagian Hukum Administrasi Negara, Universitas Andalas.

Badan Pusat Statistik, Pekanbaru Dalam Angka, 2014, hlm. 3.

Dicky A Saputro, Sudarsono, dan Lutfi Efendi, Kedudukan dan Perlindungan Hukum Tenaga Honorer Setelah Berlakunya Undang-Undang Nomor 5 tahun 2014.

Faisal Abdullah, 2015, Hukum Kepegawaian Indonesia, (Yogyakarta: Rangkang Education Yogyakarta \& PuKAP-Indonesia.

Sudi Fahmi, Adrian Faridhi. "Limited Amendment of 1945 Basic Constitution and The Return of Main State Guidelines”, Jurnal Mimbar, Volume. 36, No.1.2020.

\section{PERATURAN PERUNDANG -UNDANGAN}

Undang-Undang Nomor 5 Tahun 2014 Tentang Aparatur Sipil Negara 